\title{
RP-HPLC Method Development and Validation for Simultaneous Estimation of Aspirin, Caffeine and Orphenadrine citrate in Tablet Formulation
}

\author{
Sanjay Pai P. N. ${ }^{1}$, Sameeksha Gaude ${ }^{2}$, Anusha Palekar ${ }^{3}$ \\ Department of Pharmaceutical Analysis (Quality Assurance Group), Goa College of Pharmacy, 18th June Road, Panaji-Goa 403001, India
}

\begin{abstract}
A simple, precise and accurate RP-HPLC method has been developed and validated for the simultaneous estimation of a three component mixture - aspirin, caffeine and orphenadrine citrate. The chromatographic separation was achieved with methanol: phosphate buffer (pH 3) in the ratio of 65:35 (v/v) as mobile phase, on ACCLAIM ${ }^{T M} 120 C_{18}$ column (5 $\left.\mu \mathrm{m}, 4.6 \mathrm{X} 250 \mathrm{~mm}\right)$, at a flow rate of $1 \mathrm{ml} / \mathrm{m}$ using isocratic elution. Detection was carried out at $215 \mathrm{~nm}$. The retention time for aspirin, caffeine and orphenadrine citrate was found to be 4.2, 3.3 and $6.5 \mathrm{~m}$ respectively. The linearity range was found to be 10-100 $\mu \mathrm{g} / \mathrm{ml}$ for aspirin and 2-20 $\mu \mathrm{g} / \mathrm{ml}$ for both caffeine and orphenadrine citrate with $r^{2}$ value $0.997,0.994$ and 0.997 respectively. The mean percent recovery was found to be 97.3-97.80\% for aspirin, 95-104.3\% for caffeine and 96.36-103.4\% for orphenadrine citrate.
\end{abstract}

Keywords: Aspirin; caffeine; orphenadrine citrate; RP-HPLC

\section{Introduction}

Simultaneous analysis of drugs present in multi-component dosage forms is challenging when they are present in ratio that varies widely. Aspirin, Caffeine and Orphenadrine citrate is one such combination that is co-administered in dosage form with ratio of their presence of 77: 6: 5 respectively.

Aspirin, 2-(acetyloxy) benzoic acid is a prototypical analgesic used in the treatment of mild to moderate pain and has platelet aggregation inhibitory effect ${ }^{[1]}$. The analgesic, antipyretic and anti-inflammatory effects of aspirin are due to actions by both the acetyl and the salicylate portions of the intact molecule as well as by the active salicylate metabolite. The platelet aggregation-inhibiting activity of aspirin specifically involves the compound's ability to act as an acetyl donor to cyclooxygenase.

Caffeine,(1,3,7-trimethyl-2,3,6,7tetrahydro-1H-purine-2,6dione), a methylxanthineis a central nervous system stimulant used with NSAIDs for simple headaches ${ }^{[2]}$. Caffeine acts as an antagonist at adenosine receptors and thus promotes the release of neurotransmitters.

Orphenadrine citrate, [dimethyl(\{2-[(2-methylphenyl) (phenyl) methoxy]ethyl $\}$ ) amine is anticholinergic drug of ethanolamine antihistamine class used to treat painful muscle spasms ${ }^{[3]}$. It binds and inhibits both H1 and NMDA receptors.

Literature review reveals a validated stability indicating RPHPLC $^{[4]}$ method for the simultaneous determination of orphenadrine citrate, caffeine and aspirin in presence of aspirin degradation products, process related impurities and excipients and two derivative spectroscopic methods ${ }^{[5]}$ for the simultaneous estimation of aspirin, caffeine, and orphenadrine citrate. The objective of the present study was to develop and validate a simple, rapid, accurate and precise RP-HPLC method for the simultaneous estimation of aspirin, caffeine and orphenadrine citrate.

\section{Materials and Methods}

\section{Reagents and Chemicals}

Gift samples of aspirin and caffeine were received from West Coast Laboratories, Mumbai. Orphenadrine citrate gift sample was obtained from RL Fine Chemicals, Bangalore. The tablets were purchased from the market. HPLC grade methanol and milli $\mathrm{Q}$ water were used for analysis.

\section{Instrumentation}

HPLC, Thermo scientific - Model Ultimate 3000 equipped with variable wavelength detector was used for the study. Sample injection was manual, through rheodyne injection valve equipped with $20 \mu \mathrm{l}$ loop.The output signal was monitored and integrated using Chromeleon software.

\section{Chromatographic Conditions}

ACCLAIM TM C18 column $(250$ X $4.6 \mathrm{~mm}, 5 \mu)$ was used for separation. The mobile phase containing methanol: phosphate buffer $\mathrm{pH} 3(65: 35) \mathrm{v} / \mathrm{v}$ was delivered at the flow rate of $1 \mathrm{ml} / \mathrm{m}$ with detection wavelength set at $215 \mathrm{~nm}$.

\section{Standard Stock Solutions}

Standard stock solutions of aspirin, caffeine, and orphenadrine citrate were prepared by dissolving $10 \mathrm{mg}$ each in $10 \mathrm{ml}$ mobile phase, methanol : phosphate buffer $\mathrm{pH} 3$ $(65: 35) \mathrm{v} / \mathrm{v}$. From the stock solution, working standard solution was prepared by appropriate dilution to $10 \mathrm{ml}$ with the mobile phase. Similarly, the standard mixture of the three drugs was prepared in the mobile phase.

Application of the method to the analysis of aspirin, caffeine and orphenadrine citrate in Tablets

Tablets, 20 in number manufactured by Eon laboratories as Orphenadrine citrate -Aspirin - Caffeine tablet containing orphenadrine citrate $25 \mathrm{mg}$, aspirin $385 \mathrm{mg}$ and caffeine 30 mg were used for the study. The average weight of each tablet was determined. Tablets were powdered and an amount equivalent to $10 \mathrm{mg}$ of aspirin was transferred in to $100 \mathrm{ml}$ volumetric flask and extracted with mobile phase by shaking for $20 \mathrm{~min}$. The volume was made up with the same 


\section{International Journal of Science and Research (IJSR) \\ ISSN (Online): 2319-7064 \\ Index Copernicus Value (2013): 6.14 | Impact Factor (2014): 5.611}

solvent and filtered to obtain sample stock solution. From this $7.7 \mathrm{ml}$ was transferred to $10 \mathrm{ml}$ volumetric flask and volume made up to obtain working sample solution of the 3 drugs.

\section{Forced Degradation Studies}

Forced degradation studies were performed by subjecting the standard solution of aspirin, caffeine and orphenadrine citrate to acid hydrolysis $(0.1 \mathrm{~N} \mathrm{HCl})$, base hydrolysis $(0.1 \mathrm{~N}$ $\mathrm{NaOH}$ ), high temperature $70^{\circ} \mathrm{C}$ (for $8 \mathrm{~h}$ ), oxidation $(3 \%$ $\mathrm{H}_{2} \mathrm{O}_{2}$ ) and light (UV light for $8 \mathrm{~h}$ ). For acid and base hydrolysis as well as for oxidation studies, the samples were kept for $8 \mathrm{~h}$ at room temperature. Forced degradation at elevated temperature and light was carried out by keeping the samples in oven for $8 \mathrm{~h}$ at $70^{\circ} \mathrm{C}$, and under UV light for $8 \mathrm{~h}$ respectively.

\section{Validation}

The method was validated for specificity, linearity, accuracy, precision and robustness using ICH guidelines ${ }^{[6]}$.

\section{Specificity}

Working standard solutions of aspirin, caffeine and orphenadrine citrate were injected separately and chromatograms were recorded. Further sample solution was also injected to establish the absence of interference of excipients with active ingredients.

\section{Linearity}

The linearity of the method was determined at ten concentration levels ranging from $10-100 \mu \mathrm{g} / \mathrm{ml}$ for aspirin, $2-20 \mu \mathrm{g} / \mathrm{ml}$ for caffeine and $2-20 \mu \mathrm{g} / \mathrm{ml}$ for orphenadrine citrate. The linearity graph was obtained by plotting the area vs. concentration. The regression equation of the calibration curves were $\mathrm{y}=0.837 \mathrm{x}+1.032$ for aspirin, $\mathrm{y}=2.187 \mathrm{x}$ 1.318 for caffeine and $y=0.739 x-0.026$ for orphenadrine citrate.

\section{Accuracy}

Method accuracy was performed by spiking the known amounts of each drug to the sample solution and then comparing the spiked concentration with the found concentration. The three levels of solutions were made corresponding to $80 \%, 100 \%$ and $120 \%$, of the nominal target analyte concentration. Each level was made in triplicate. The percentage recovery in each case was calculated.

\section{Precision}

Precision was determined in six replicates of the sample solution on the same day to find out the intra-day precision. The results were expressed as \%RSD of the measurements.

\section{Robustness}

Robustness of the method was determined by making small deliberate changes in the $\mathrm{pH}$ of the mobile phase \pm 0.2 of the optimized $\mathrm{pH}$ and flow rate $\pm 0.2 \mathrm{ml}$.

\section{Results and Discussion}

The aim of this study was to develop and validate a novel RP-HPLC method for the simultaneous analysis of aspirin, caffeine and orphenadrine citrate using a commonly used reverse phase $\mathrm{C} 18$ column. Initially, preliminary trials were carried out to select optimum chromatographic conditions. The chromatographic parameters such as mobile phase ratio, $\mathrm{pH}$, and detection wavelength were studied. The mobile phase containing methanol: phosphate buffer pH3 (65:35) $(\mathrm{v} / \mathrm{v})$ with a flow rate of $1 \mathrm{ml} / \mathrm{m}$ was selected as the optimized mobile phase since all the drugs showed good resolution between the peaks, optimum retention time and tailing factor was less than 2 (Fig. 1). Since the UV overlain spectra of aspirin, caffeine and orphenadrine citrate showed that all the drugs showed adequate response at $215 \mathrm{~nm}$, it was selected as the detection wavelength for the study (Fig. 2). The retention times of aspirin, caffeine and orphenadrine citrate were found to be $4.2 \mathrm{~m}, 3.3 \mathrm{~m}$ and $6.5 \mathrm{~m}$ respectively.

The system suitability tests were carried out on the standard solutions and the parameters are summarized in Table 1. The values obtained suggest the suitability of the system for the analysis of these drugs in the synthetic mixture. The calibration curves of aspirin, caffeine and orphenadrine citrate were constructed by plotting the peak area (y-axis) to the concentration (x-axis). It was found to be linear with a correlation coefficient of $0.997,0.994$ and 0.997 respectively which shows that good correlation exists between area of the peak and concentration. This method was validated for intraday precision, \% RSD of assay when analysis was carried out six times on a given day was found be $0.323,0.466$ and 1.35 for aspirin, caffeine and orphenadrine citrate respectively. The results obtained were within the acceptance limits. The robustness of the method was studied by altering the chromatographic conditions slightly like $\mathrm{pH}$ of mobile phase and flow rate. The result of analysis was found to be acceptable as it ranged from $90 \%$ to $110 \%$ for all the three drugs. Forced degradation studies were performed on the mixture. Aspirin, caffeine and orphenadrine showed degradant peaks under base hydrolysis. Caffeine and aspirin also showed significant degradation when hydrolyzed with acid. The degradant peaks obtained under all the above conditions did not interfere with the drug peaks confirming the stability indicating method for the analysis. The developed method was successfully applied for the simultaneous determination of aspirin, caffeine and orphenadrine citrate in the marketed tablet formulation and the results of the assay were comparable with the corresponding labeled amounts. The percent mean recovery values were found to be 95 $104.3 \%$ for caffeine, 97.31-97.80\% for aspirin and 96.36$103.4 \%$ for orphenadrine citrate. Acceptable recovery values and no additional peaks in the chromatogram indicate that the developed method is accurate and specific, and can be used for the routine analysis of aspirin, caffeine and orphenadrine citrate in their synthetic mixture.

\section{Conclusion}

The study describes a novel RP-HPLC method for the estimation of aspirin, caffeine and orphenadrine citrate in the marketed sample of Orphenadrine citrate-Aspirin-Caffeine Tablets. The method gives good resolution between compounds with a short analysis time. The method is validated and is simple, sensitive, accurate and precise. 


\section{International Journal of Science and Research (IJSR) \\ ISSN (Online): 2319-7064}

Index Copernicus Value (2013): 6.14 | Impact Factor (2014): 5.611

\section{Acknowledgement}

Authors wish to thank R L Fine Chemicals, Bangalore and West Coast Laboratories Mumbai for providing the gift samples of orphenadrine citrate, caffeine and aspirin. The authors are also thankful to Dr. G.K. Rao, Principal, Goa College of Pharmacy for providing the necessary facilities to carry out the research activity.

\section{References}

[1] Drug profile. [homepage on the Internet]. 2013 [cited 2015 Oct 16]. Available from: http://www.drugbank.ca/drugs/db00945

[2] Drug profile. [homepage on the Internet]. 2013 [cited 2015 Oct 16]. Available from: http://www.drugbank.ca/drugs/DB00201
[3] Drug profile. [homepage on the Internet]. 2013 [cited 2015 Oct 16]. Available from: https://en.wikipedia.org/wiki/Orphenadrine

[4] Darwish K, Salama I, Mostafa S, et al. Validated Stability-Indicating Reversed-Phase-HPLC method for simultaneous determination of orphenadrine citrate, caffeine and aspirin. Chem. Pharm. Bull. 2012; 60(11):1426-36.

[5] Abdel-hay MH, Galal SM, Ragab MA. Application of Derivative and Derivative-ratio Spectrophotometry in the Determination of a Binary Mixture of Naproxen and Diflunisal and a Ternary Mixture of Orphenadrine, Caffeine and Aspirin. Taiwan Pharm J. 2007; 59(4):15770.

[6] International Conference on Harmonization. Validation of analytical procedures: Methodology Q2B, International Conference on Harmonization. Geneva: IFPMA; 1997.

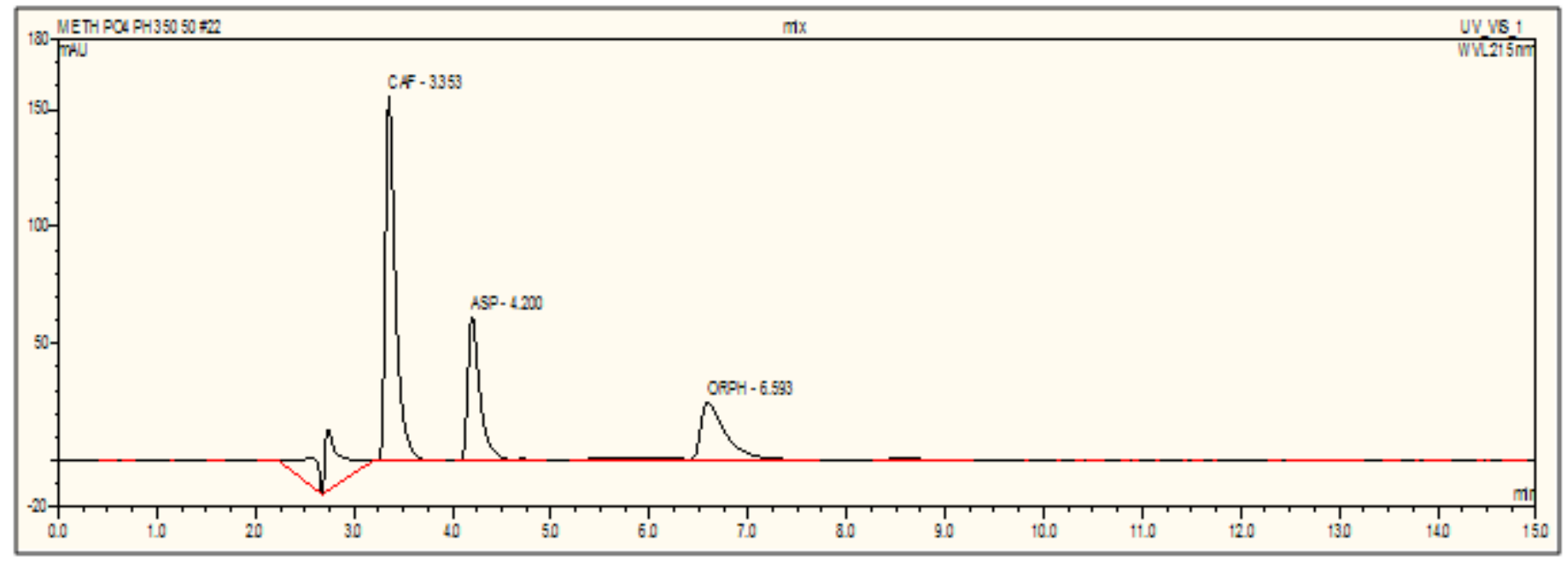

Figure 1: Chromatogram of Aspirin, Caffeine and Orphenadrine citrate

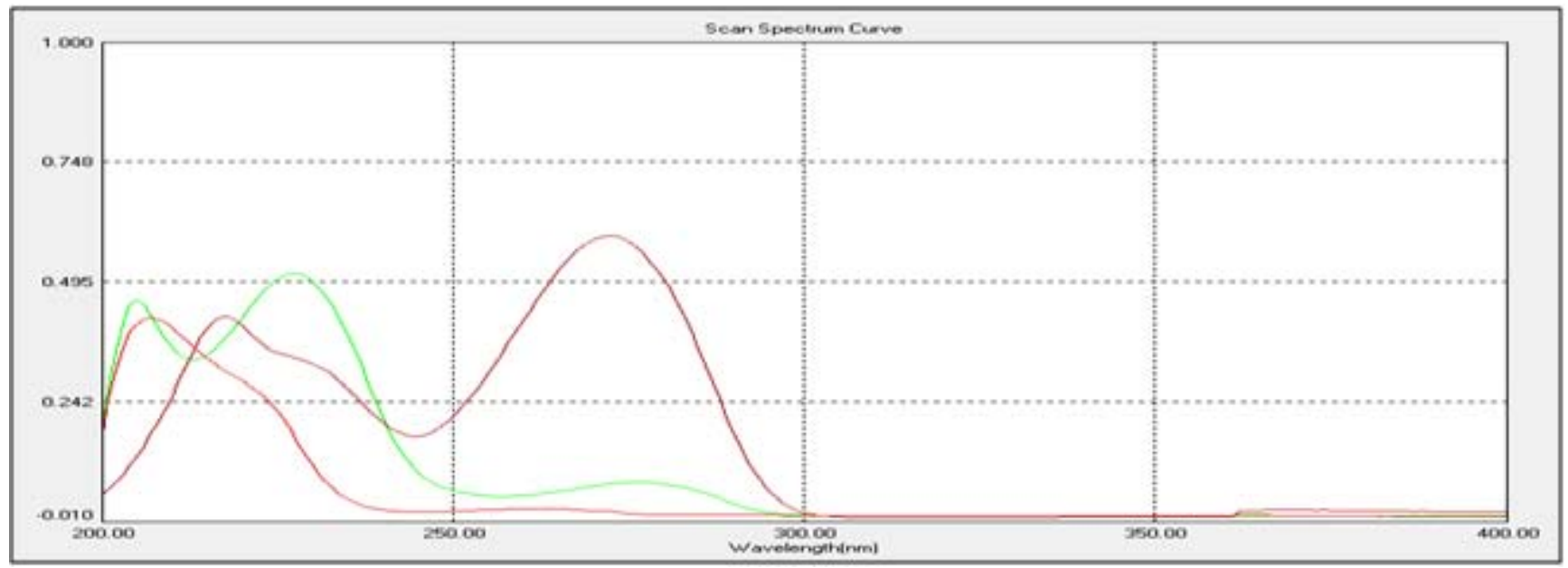

Figure 2: Overlain UV Spectra of Aspirin, Caffeine \& Orphenadrine citrate in mobile phase 


\section{International Journal of Science and Research (IJSR) \\ ISSN (Online): 2319-7064}

Index Copernicus Value (2013): 6.14 | Impact Factor (2014): 5.611

Table 1: Validation and System suitability Parameters of the method

\begin{tabular}{|c|c|c|c|}
\hline Parameters & Aspirin & Caffeine & Orphenadrine citrate \\
\hline Theoretical plates & 7388 & 6602 & 4756 \\
\hline Resolution & \multicolumn{3}{|c|}{6.49522 .678} \\
\hline Asymmetry factor & 1.49 & 1.53 & 1.67 \\
\hline Retention Time $(\mathrm{min})$ & 4.2 & 3.3 & 6.5 \\
\hline Linearity range $(\mu \mathrm{g} / \mathrm{ml})$ & $10-100$ & $2-20$ & $2-20$ \\
\hline $\begin{array}{c}\text { Regression Equation } \\
\text { *y=mx+c }\end{array}$ & $\mathrm{y}=0.837 \mathrm{x}+1.032$ & $\mathrm{y}=2.187 \mathrm{x}-1.318$ & $\mathrm{y}=0.739 \mathrm{x}-0.026$ \\
\hline Correlation coefficient & 0.9975 & 0.9946 & 0.9971 \\
\hline Intra day Precision $(\%$ RSD) & 0.323 & 0.466 & 1.35 \\
\hline
\end{tabular}

Table 2: Results of the Accuracy study:

\begin{tabular}{|l|c|c|c|c|}
\hline \multirow{2}{*}{ Drug } & $\begin{array}{c}\text { Recovery } \\
\text { level }\end{array}$ & $\begin{array}{c}\text { Amount } \\
\text { added } \\
(\mu \mathrm{g} / \mathrm{ml})\end{array}$ & $\begin{array}{c}\text { Amount } \\
\text { recovered } \\
(\mu \mathrm{g} / \mathrm{ml})\end{array}$ & $\begin{array}{c}\% \\
\text { Recovery }\end{array}$ \\
\hline Aspirin & $80 \%$ & 30.8 & 30.20 & 98.04 \\
\cline { 2 - 5 } & $100 \%$ & 38.5 & 38.05 & 98.88 \\
\cline { 2 - 5 } & $120 \%$ & 46.2 & 45.51 & 98.50 \\
\hline Caffeine & $80 \%$ & 2.4 & 2.54 & 105 \\
\cline { 2 - 5 } & $100 \%$ & 3 & 2.87 & 95.66 \\
\cline { 2 - 5 } & $120 \%$ & 3.6 & 3.40 & 95.2 \\
\hline Orphenadrine citrate & $80 \%$ & 2 & 2.04 & 102 \\
\cline { 2 - 5 } & $100 \%$ & 2.5 & 2.44 & 97.64 \\
\cline { 2 - 5 } & $120 \%$ & 3 & 3.10 & 103.6 \\
\hline
\end{tabular}

